\title{
Micro-mechanical approach for the vibration analysis of CFRP laminates under impact-induced damage
}

\author{
Marco A. Pérez ${ }^{\mathrm{a}, \mathrm{c}, *}$, Sergio Oller ${ }^{\mathrm{b}, \mathrm{c}}$, Carlos A. Felippa ${ }^{\mathrm{d}}$, Lluís Gil ${ }^{\mathrm{a}, \mathrm{c}}$ \\ ${ }^{a}$ Laboratory for the Technological Innovation of Structures and Materials (LITEM), Colon 11, TR45, Terrassa, 08222 Barcelona, Spain \\ ${ }^{b}$ International Center for Numerical Methods in Engineering (CIMNE), Gran Capità s/n, Edifici C1, 08034 Barcelona, Spain \\ ${ }^{c}$ Departament de Resistència de Materials i Estructures a l'Enginyeria, Universitat Politècnica de Catalunya - BarcelonaTech, Spain \\ ${ }^{d}$ Department of Aerospace Engineering Sciences and Center for Aerospace Structures, University of Colorado, Campus Box 429, Boulder, CO 80309-0429, USA
}

\begin{abstract}
This paper deals with modeling the effect of low-velocity impact damage upon the vibration response of CFRP laminates through a micro-mechanical description of the induced internal damage. The serial-parallel (SP) continuum approach is used to estimate the map of induced internal damage by considering the micro-structural interaction between the composite constituents and modifying their constitutive performance through a continuum damage formulation. An eigenvalue analysis is then done to determine the modal response of impacted laminates. The validity of the modeling approach to successfully reproduce the vibration response of impacted coupons is assessed through a comparison with an experimental test series conducted on a set of 48 CFRP laminated coupons. The results confirm the ability of the described approach in comparison to competing ones used to reproduce the experimentally observed behaviour.
\end{abstract}

Keywords: B. Impact behaviour, B. Vibration, C. Micro-mechanics, C. Finite element analysis (FEA)

\section{Introduction}

Composite laminates are being extensively used in advanced structural applications because of their appealing advantages when being compared to traditional structural materials. Nevertheless, these materials have also shown a susceptibility to impact damage due to lack of plastic deformation, low interlaminar strength and the laminated construction to reduce the anisotropic nature of the plies [1]. Experimental studies consistently indicate that impact-induced damage combines three main failure modes: matrix cracking, delamination and fibre breakage, among which delamination is the most severe because it may severely degrade the stiffness and strength of the composite laminate, thus compromising the residual bearing capacity of the structural component and causing a collapse under unacceptable compressive load levels [2]. For these reasons, over the years, a massive amount of research activity has been devoted to developing non-destructive evaluation techniques to identify this type of damage at an early stage, as well as numerical methodologies that can quantitatively predict the performance and durability of composite structures under impact events.

Among different non-destructive experimental approaches, the so-called vibration-based Non-Destructive Testing (NDT) methods have been shown to be useful tools for damage identification in laminated composites, since, in contrast to other assessment methods, these techniques provide global informa-

\footnotetext{
${ }^{*}$ Corresponding author.

Email address: marco.antonio.perez@upc.edu (Marco A. Pérez)
}

tion, does not necessarily require that the vicinity of the damage site to be known in advance and can be employed under in-service conditions. The overall principle underlying these methods is that vibration response depends on the physical properties of the structure (mass, damping and stiffness); therefore, changes that occur in physical properties due to damage can result in detectable variations in the response, which can serve as an indicator of structural integrity [3]. Based on this phenomenon, a considerable number of contributions in the field have appeared, e.g. [4-14]. These methods can be broadly classified into two approaches: response-based methods that use only experimental data to identify damage, and model-based methods that require numerical models. The experimental approaches have mostly focused on measuring the vibration response before and after damaging the composite, analysing the data in both the frequency and modal domains. On the other hand, the effectiveness of the model-based methods is highly dependent on the accuracy of the numerical model used. This fact is of utmost importance when applied to impact identification in composite laminates because, as stated before, induced damage is a complex mixture of multiple failure modes interacting with each other [15].

The complexity of the failure modeling in composite structures arises from the heterogeneous microstructure of composite materials. This fact represents a departure from the way that conventional materials are modeled and consequently requires unconventional approaches to dealing with them. The different entities involved, i.e. component materials, ply and laminate, span a spectra of length scales that clearly dictates the analysis approach. Over the years, due to the increased computing 
capabilities, research efforts have shifted from the macroscale towards the microscale.

Earlier attempts made to numerically analyse the vibration behaviour of damaged laminates focused exclusively on delamination failure. In these approaches the delaminated laminate was based on the well-known Crack Opening Displacement (COD) [16, 17], divided into sublaminates and continuity conditions were imposed at the delamination region. Each of these sublaminates was analysed using the equivalent single layer theories [18]. Other reported investigations were based on the layerwise theory, wherein the delamination is modeled as an embedded layer or by introducing discontinuity functions in the in-plane and through-the-thickness displacement fields [5]. These studies have mainly established a basic understanding of the influence of delamination failure mode on the vibration response.

More recent publications address the issue within the framework of the mesoscale, wherein a lamina is considered as a homogeneous, although anisotropic, material and damage is incorporated through the application of Continuum Damage Mechanics (CDM) at the ply level. CDM approaches are based on material degradation models that allow simulating the material behaviour after the onset of damage [19-21]. Using appropriates failure criteria in combination with interface elements to account for interply decohesion, these approaches have proved

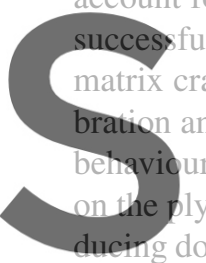
ul for predicting different racking, delamination and analysis can be performed ur by considering the influen compliance through scal ominant stiffness and stress c
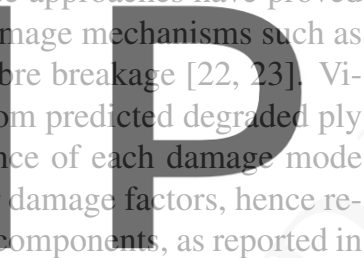

[10]. It should be pointed out that the main limitation of these

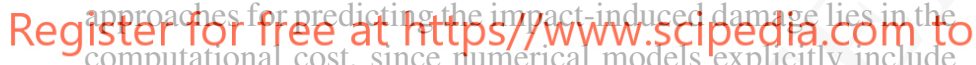
each individual ply as well as the interfaces between them.

Current deveiopments are focused primarily on the microscale. These have proven to be suitable to accurately predict the composite mechanical performance [24-30]. This is due to the fact that failure processes of composite structures are governed by micro-structural phenomena since the failure mechanisms of composites are caused by the micro-structural complex interaction between its constituents. Obviously, this lowscale level approach does not resolve the issue of the computational cost, but presents several significant advantages when compared to the previous methods. For instance, complex behaviour when one of the constituents gets into the non-linear range can be accounted for.

Bearing this in mind, this paper addresses the modeling of the effect upon the vibration response of low-velocity impactinduced damage on CFRP laminated plates, by means of a micro-mechanical approach based on the serial/parallel mixing theory. This paper fits within the work conducted by the authors [6, 15, 31-33]. The bottom-up implementation is aimed to determine the macroscopic behaviour of the damaged heterogeneous material by understanding the micro-structural interaction between the composite constituents and modifying their constitutive performance. Damage is included within the framework through the application of CDM at the constituents' materials level. Interply and fibre damage are captured within the same framework, hence does not require use of interface elements to account for interply decohesion, nor explicitly modeling each individual ply, hence resulting in a computationally less demanding simulation. The validity of the approach to successfully predict the vibration response of impacted laminates is assessed by comparing the numerical results with those obtained from an extensive experimental campaign that shows good agreement.

The following section describes the micro-mechanical approach used to determine the map of internal induced damage as well as the bottom-up scale modeling procedure to estimate the vibration behaviour of impact damaged laminates. In section 3 , numerical procedures undertaken to simulate the low-velocity impact event together with the modeling of the vibration response from three different damage approaches are presented. In section 4, the experimental methodology is described and details and requirements of the tests are given. Subsequently, numerical and experimental results are presented, compared and discussed in section 5. Finally, the conclusions of the work are presented.

\section{Micro-mechanical approach}

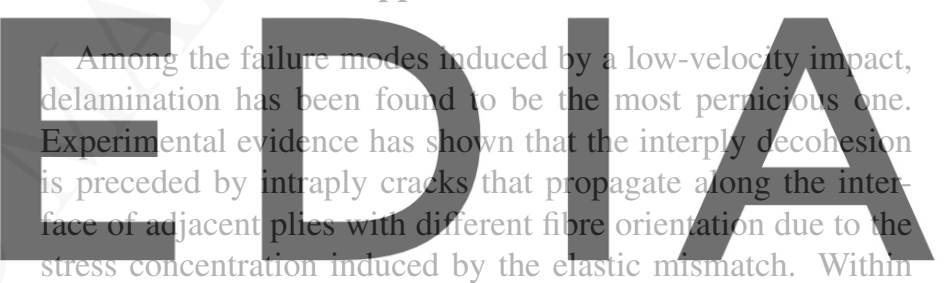

the framework of the micro-mechanical analysis, the matrix

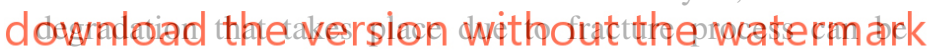
addressed by using an isotropic continuum damage formulation [34], which is based on the effective stress concept introduced by Kachanov in 1958 [35, 36]. The damage model assumes a reduction of the effective area of the material by the formation of a homogeneous distribution of cracks. The constitutive behaviour of the damaged material can be expressed mathematically as a function of one-parameter scalar ${ }^{m} d \in[0,1)$ as:

$$
{ }^{m} \boldsymbol{\sigma} \equiv\left(1-{ }^{m} d\right){ }^{m} \boldsymbol{\sigma}_{0}=\left(1-{ }^{m} d\right){ }^{m} \mathbb{C}_{0}{ }^{m} \boldsymbol{\varepsilon}
$$

where the superscripts $m$ indicate matrix. The scalar degradation parameter ${ }^{m} d$ stands for the areal density of microcracks and is used to transform the real damaged stress tensor ${ }^{m} \boldsymbol{\sigma}$ into an effective stress tensor ${ }^{m} \boldsymbol{\sigma}_{0}$ corresponding to the matrix undamaged configuration, being ${ }^{m} \mathbb{C}_{0}$ the constitutive tensor of the undamaged material and ${ }^{m} \boldsymbol{\varepsilon}$ the strain tensor. The same approach can be followed to characterize fibre degradation through the scalar parameter ${ }^{f} d \in[0,1)$ as discussed below. The prediction of the internal damage parameters, as well as ${ }^{m} d$ and ${ }^{f} d$, and the corresponding impact-damage induced map, deserves further attention.

The fundamental problem in micro-mechanics of heterogeneous materials is estimation of the relation between the average strains in the spatially uniform component materials, i.e. 
${ }^{f} \boldsymbol{\varepsilon}$ and ${ }^{m} \boldsymbol{\varepsilon}$, with the average or macroscopic strain. For that purpose, this work makes use of the serial-parallel (SP) continuum approach developed by Rastellini et al. [37] and Martinez et al. [31], which makes the composite behaviour dependent on both the constitutive laws of the component materials according to their volumetric fraction and to their kinematics interaction and morphological distribution inside the composite. The model is essentially based on an appropriate management of the constitutive laws of component phases within a continuum framework by making use of suitable closure equations that characterize the composite micro-mechanics kinematics. The formulation used is thoroughly described in references $[31,38]$ and will not be elaborated here except for key aspects that are briefly described in the following.

The SP continuum approach was developed assuming that the components of the composite behave as parallel in the fibres alignment direction and as serial in the orthogonal direction. Consequently, it defines an iso-strain condition in the fibre (parallel) direction and an iso-stress condition in the transversal (serial) direction (see Fig. 1). The composite strain tensor ${ }^{c} \varepsilon$ is then decomposed into its parallel $\left({ }^{c} \varepsilon_{P}\right)$ and serial $\left({ }^{c} \varepsilon_{S}\right)$ components by using fourth-order projector tensors $\mathbb{P}_{P}$ and $\mathbb{P}_{S}$, respectively, as follows:

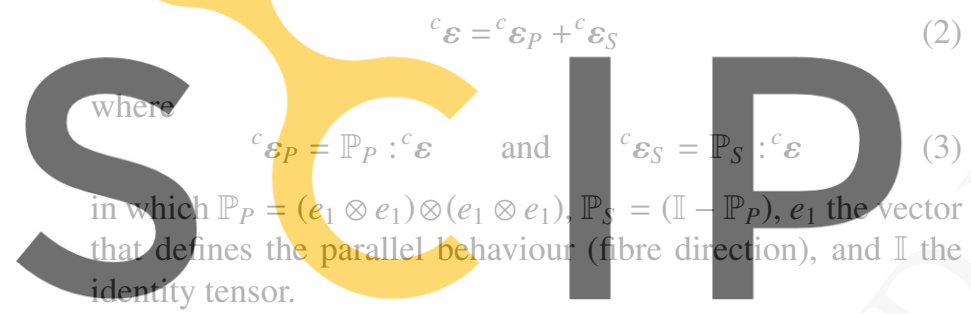

The compatibility or closure equations that define the stress

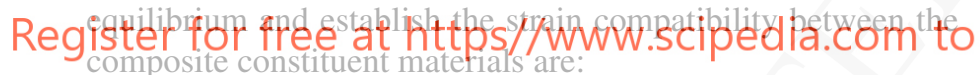

$$
\begin{array}{cl}
\text { Parallel behaviour: } & \left\{\begin{array}{c}
{ }^{c} \boldsymbol{\varepsilon}_{P}={ }^{f} \mathcal{E}_{P}={ }^{m} \mathcal{\varepsilon}_{P} \\
{ }^{c} \boldsymbol{\sigma}_{\boldsymbol{P}}={ }^{f} v^{f} \boldsymbol{\sigma}_{\boldsymbol{P}}+{ }^{m} v^{m} \boldsymbol{\sigma}_{P}
\end{array}\right. \\
\text { Serial behaviour: } \quad\left\{\begin{array}{c}
{ }^{c} \boldsymbol{\varepsilon}_{S}={ }^{f} \boldsymbol{v}^{f} \boldsymbol{\varepsilon}_{S}+{ }^{m} v^{m} \boldsymbol{\varepsilon}_{S} \\
{ }^{c} \boldsymbol{\sigma}_{S}={ }^{f} \boldsymbol{\sigma}_{S}={ }^{m} \boldsymbol{\sigma}_{S}
\end{array}\right.
\end{array}
$$

where superscripts $c, f$ and $m$ stands for composite, fibre and matrix, respectively, and ${ }^{i} v$ is the volume-fraction coefficient of each composite constituent. As observed, ${ }^{f} \boldsymbol{\varepsilon}_{P}$ and ${ }^{m} \boldsymbol{\varepsilon}_{P}$ are obtained straightforward from the composite strains. However, the compatibility equations are not easily fulfilled in the transversal direction, for which it is necessary to make an initial prediction on the fibre or matrix serial strain. Once the strains tensors of both components are determined, their stress tensors are calculated using a given constitutive law. It is possible to simulate the composite constituents with a non-linear behaviour law, such as damage or plasticity, as has been proved in previously works [31].

Each fibre is considered to be homogeneous, transversely isotropic, with a linearly elastic behaviour. Fibre breakage is assumed to be the only ultimate failure mode, whereas the matrix is assumed to be homogeneous, isotropic and viscoplastic. The onset of matrix damage (i.e. ${ }^{m} d>0$ ) can be predicted by the norm of the principal stresses tensor (or other classical scalar threshold stress function) as:

$$
F\left({ }^{m} \sigma_{0}\right)=\left[\frac{\sum_{I=1}^{3}\left\langle{ }^{m} \sigma_{I}\right\rangle}{\left.\sum_{I=1}^{3}\right|^{m} \sigma_{I} \mid} \frac{{ }^{m} \sigma_{c}}{{ }^{m} \sigma_{t}}+\left(1-\frac{\sum_{I=1}^{3}\left\langle{ }^{m} \sigma_{I}\right\rangle}{\left.\sum_{I=1}^{3}\right|^{m} \sigma_{I} \mid}\right)\right]\left\|^{m} \sigma_{I}\right\|
$$

where the first term is a weighting function that accounts for a different degradation path for tensile and compressive stresses, with ${ }^{m} \sigma_{t}$ and ${ }^{m} \sigma_{c}$ being the tensile and the compressive matrix ultimate strengths, respectively. \langle\rangle stands for the Macaulay brackets defined as $\langle x\rangle=\frac{1}{2}(x+|x|)$.

The variation of the damage parameter ${ }^{m} d$ is obtained by using an exponential strain-softening law [34] expressed as:

$$
{ }^{m} d=1-\frac{{ }^{m} \sigma_{\max }}{F\left({ }^{m} \boldsymbol{\sigma}_{0}\right)} e^{A\left(1-\frac{F\left({ }^{m} \boldsymbol{\sigma}_{0}\right)}{{ }^{m} \sigma_{\max }}\right)}
$$

where ${ }^{m} \sigma_{\max }$ denotes the damage threshold defined as a material property, $F\left({ }^{m} \sigma_{0}\right)$ is the yield function and the parameter $A$ depends upon the material fracture energy as follows:
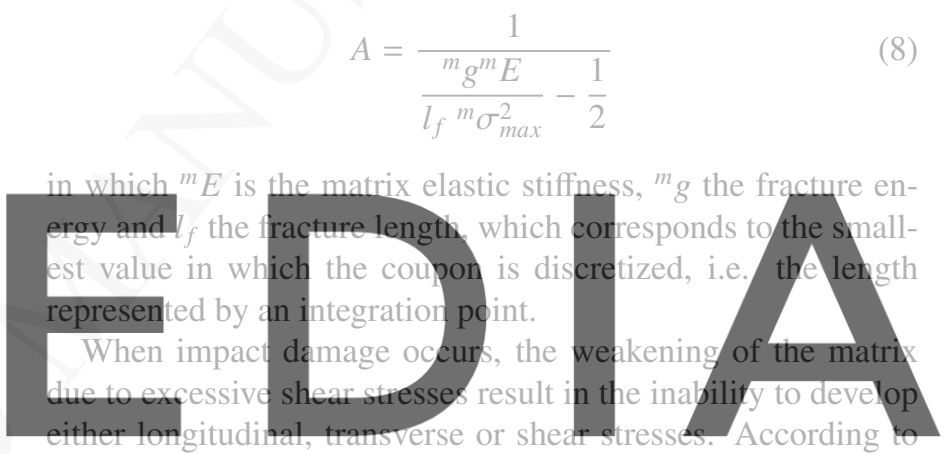

the above compatibility equations, when the matrix reaches a

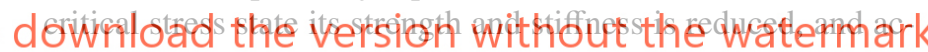
cordingly the whole composite performance is also reduced in the transversal direction. Given that shear stresses are defined through the serial condition, the composite shear strength and stiffness are reduced as happens in a delaminated composite. One significant advantage is that intraply and interply damages are captured within the same framework.

This approach can be roughly interpreted as a phenomenological homogenisation. It has proven to be capable of successfully simulate the composite structural performance when applied to a low-velocity impact problem, especially to predict the phenomenon of initiation and propagation of interlaminar damage [15]. This allows the estimation of the impact-damage induced map and thus the corresponding internal damage parameters ${ }^{f} d$ and ${ }^{m} d$ required to subsequently investigate the effect of impact-induced damage on the vibration response.

Assuming the lamina to be macroscopically homogeneous by focusing on the average response, the effective engineering constants of the lamina reinforced with continuous unidirectional fibres aligned in the 1 direction, are calculated in terms of the elastic properties of the constituent materials and their concentrations through the following approximate expressions developed through a simplified strength of materials approach [39]:

$$
{ }^{c} E_{1}^{d}={ }^{f} v\left(1-{ }^{f} d\right){ }^{f} E_{1}+\left(1-{ }^{f} v\right)\left(1-{ }^{m} d\right){ }^{m} E
$$




$$
{ }^{c} E_{2}^{d}=\frac{1}{\frac{\sqrt{f_{v}}}{\sqrt{f_{v}}\left(1-{ }^{f} d\right){ }^{f} E_{2}+\left(1-\sqrt{f_{v}}\right)\left(1-{ }^{m} d\right)^{m} E}+\frac{1-\sqrt{f_{v}}}{\left(1-{ }^{m} d\right)^{m} E}}
$$

$$
{ }^{c} G_{12}^{d}=\frac{1}{\frac{\sqrt{f_{v}}}{\sqrt{f_{v}}\left(1-{ }^{f} d\right){ }^{f} G_{12}+\left(1-\sqrt{f_{v}}\right)\left(1-{ }^{m} d\right)^{m} G}+\frac{1-\sqrt{f_{v}}}{\left(1-{ }^{m} d\right)^{m} G}}
$$

$$
{ }^{c} G_{23}^{d}=\frac{1}{\frac{\sqrt{f_{v}}}{\sqrt{f_{v}}\left(1-{ }^{f} d\right){ }^{f} G_{23}+\left(1-\sqrt{f_{v}}\right)\left(1-{ }^{m} d\right)^{m} G}+\frac{1-\sqrt{f_{v}}}{\left(1-{ }^{m} d\right)^{m} G}}
$$

$$
{ }^{c} v_{12}={ }^{f} v v_{v_{12}}+\left(1-{ }^{f} v\right)^{m} v
$$

where the superscripts $c, f$ and $m$ stands for composite, fibre and matrix, respectively, $E_{i}$ are the elastic moduli in the $i^{\text {th }}$ direction, $v_{i j}$ the Poisson's ratios, $G_{i j}$ the shear moduli and ${ }^{f} v$ is the fibre volume-fraction coefficient. The superscripts $d$ indicate the effective ply degraded modulus affected by the scalar degradation parameters.

For a lamina that behaves as a linear orthotropic solid, the strains and stresses relationship is given by the effective compliance matrix $\mathbf{S}\left({ }^{f} d,{ }^{m} d\right)$ expressed by

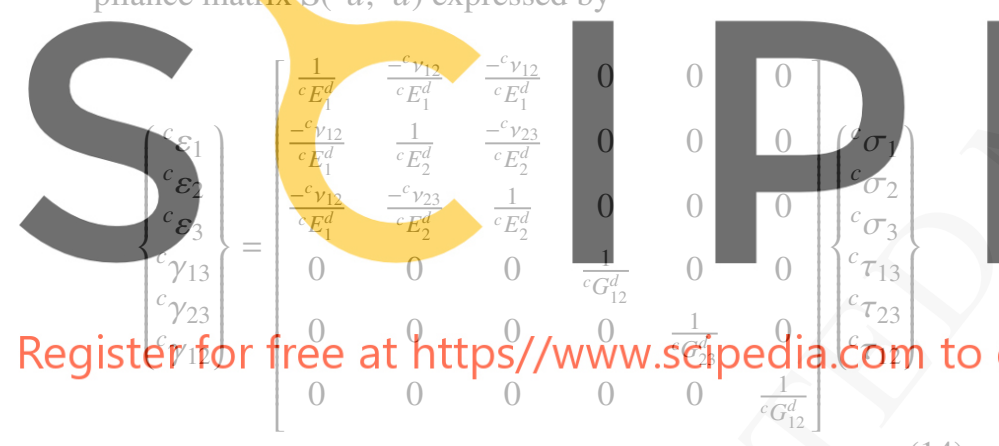

(14)

where the ply is considered to be transversely isotropic, correspondingly: ${ }^{c} E_{3}={ }^{c} E_{2},{ }^{c} G_{13}={ }^{c} G_{12},{ }^{c} v_{13}={ }^{c} \nu_{12}$ and

$$
{ }^{c} v_{23}=\frac{{ }^{c} E_{2}^{d}}{2^{c} G_{23}^{d}}-1
$$

It should be noticed that the scalar damage model used does not account for directionality of damage. Nonetheless anisotropic damage effects on the macroscale are taken into account by means of the stacking sequence of the laminate, i.e. damage formulation is applied to each layer of the composite and, afterwards, the composite behaviour is computed by combining the performance of each constituent layer.

For the computation of the damage map prediction in the laminated structure, the general dynamic differential equation was solved by an explicit time integration scheme implemented in the explicit FE code ComPack (see Appendix), wherein the stiffness matrix is not assembled [40]. Only the mass, the nodal displacements, velocities and accelerations vectors are involved. However, to determine the eigenfrequencies and eigenvectors of the system, the mass $\mathbf{M}$ and stiffness $\mathbf{K}$ assembled matrices are necessary to solve the eigenvalue equation, expressed as:

$$
\mathbf{\Omega M \Phi}=\mathbf{K \Phi}
$$

where $\boldsymbol{\Omega}=\operatorname{diag}\left[\omega_{1}^{2} \cdots \cdots \omega_{n}^{2}\right]$ is the diagonal matrix of eigenfrequencies and $\Phi=\left[\begin{array}{lll}\phi_{1} & \cdots & \phi_{n}\end{array}\right]$ are the corresponding eigenvectors. Therefore, a specifically devised FE Matlab code was used

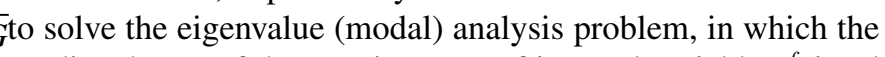
predicted map of damage in terms of internal variables ${ }^{f} d$ and ${ }^{m} d$ was introduced on Gauss points of each finite element. The mass and stiffness element matrices are given by:

$$
\begin{gathered}
\mathbf{M}^{e}=\int_{V^{e}} \rho \mathbf{N}^{T} \mathbf{N} d V \\
\mathbf{K}^{e}=\int_{V^{e}} \mathbf{B}^{T} \mathbf{C}\left({ }^{f} d,{ }^{m} d\right) \mathbf{B} d V
\end{gathered}
$$

being and $\mathbf{N}$ and $\mathbb{B}$ are respectively the shape functions and strain matrices for the element. Details of the formulation may be found in [41].

\section{Numerical analysis}

The numerical study conducted to analyse the vibration re-

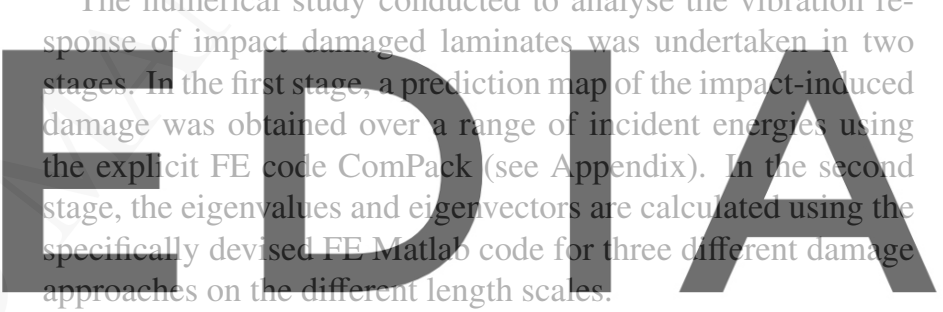

downAlearduthe version without the watermark

The monolithic quasi-isotropic composite specimen modeled was composed of 40 unidirectional CFRP plies with a balanced and symmetric stacking sequence $\left[45^{\circ} / 0^{\circ} /-45^{\circ} / 90^{\circ}\right]_{55}$. The laminated plate layup was defined such that the $0^{\circ}$ fibre orientation was aligned with the lengthwise dimension. The size of the plate sample was $150 \times 100 \times 5.2 \mathrm{~mm}^{3}$. The component mechanical properties and calculated homogenised ply mechanical properties are listed in Table 1. Transverse constituent properties given in [42] are used throughout this work to complete data provided by manufacturers.

\subsection{Drop-weight impact simulation}

The geometrical model depicted in Fig. 1 was built to reproduce the experimental setup described in the standard test method ASTM D7136 [43]. The virtual coupon consists of a $75 \times 50 \times 5.2 \mathrm{~mm}^{3}$ rectangular parallelepiped which corresponds to one quarter of the overall geometry of the laminate. This simplification assumes a double symmetry in the internal damage distribution to significantly reduce the computational cost. The virtual coupon was simply supported on the base and was fixed preventing the movement in the out-of-plane direction during the impact of a hemispherical projectile. The impactor diameter was $16 \mathrm{~mm}$, according to the standard test method. The 


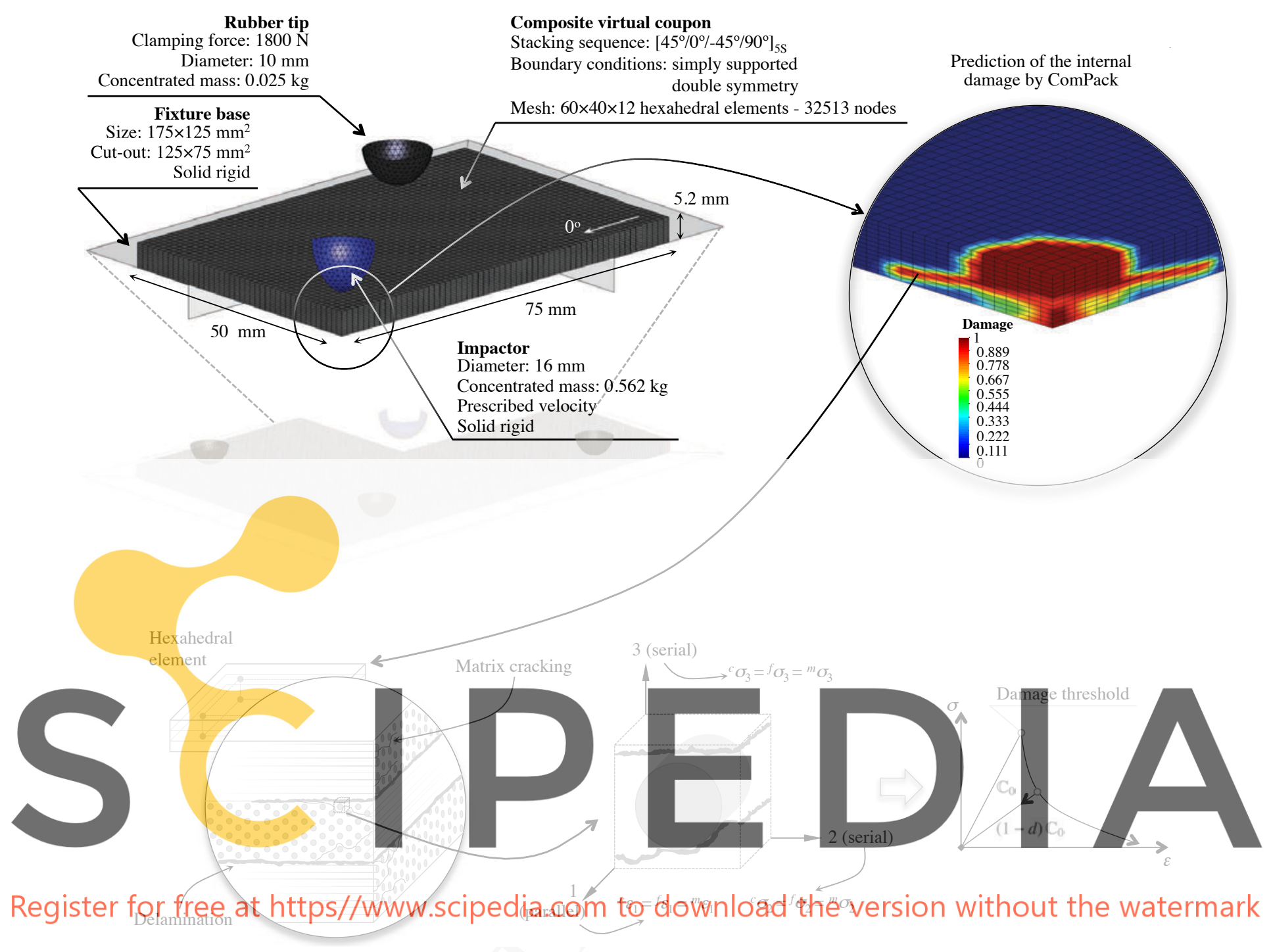

Figure 1: Finite Element model built for the numerical simulation of drop-weight impact test and numerical prediction of the through-thickness distribution of damage for a $50 \mathrm{~J}$ simulated impact on the composite virtual coupon (top). The variable plotted corresponds to the element average damage. Scheme of the serial-parallel continuum mechanics approach (bottom).

fixture base and the impactor were modeled as solid rigid bodies. Only the holder and the composite virtual coupon were considered deformable parts.

The primary objective of this numerical simulation was to determine the map of induced damage and in particular the delamination failure. This is an inherently three-dimensional phenomenon. Accordingly, hexahedral continuum solid elements with eight nodes and full integration were used to model the composite coupon since all components of the strain and stress tensors are included in the formulation. As stated above, the use of the SP continuum mechanics approach has the chief advantage over competing approaches of not needing interface elements to capture the phenomenon of initiation and propagation of interlaminar damage. Consequently, the through-thickness discretization of the composite virtual coupon can be done by collapsing several layers into a single element on the basis of the mixing theory through the volumetric participation, leading to a significantly decrease of the computational time required to perform the simulation. A finite element mesh of $60 \times 40$ with 12 elements in the through-thickness direction was selected to achieve an optimal performance, leading to a total of 32513 nodes. This procedure does not necessarily compromise the accuracy of the results as it is shown in $[15,31]$.

Numerical simulations were carried out for each level of the incident impact energy conducted on the experimental program as described in the next section. The impactor was modeled by defining the initial position of $1 \mathrm{~mm}$ onto the laminate and a vertical prescribed velocity consistent with the incident impact energy. Contacts were defined to set up the set of contact parts pairs, in order to avoid interpenetration between parts. The numerical results provided a map of induced damage in terms of internal variables ${ }^{f} d$ and ${ }^{m} d$ on each Gauss point of the finite element, which was employed in the subsequent stage to characterize the ply-group degraded behaviour. 
Table 1: Mechanical properties of the composite constituents and lamina. Fibre properties

\begin{tabular}{|c|c|c|}
\hline Type & \multicolumn{2}{|c|}{ Grafil TR30S 3K } \\
\hline Density & $f_{\rho}$ & $1790 \mathrm{~kg} / \mathrm{m}^{3}$ \\
\hline Longitudinal modulus & ${ }^{f} E_{1}$ & $235 \mathrm{GPa}$ \\
\hline Transverse modulus ${ }^{\dagger}$ & ${ }^{f} E_{2}$ & $15 \mathrm{GPa}$ \\
\hline In-plane shear modulus ${ }^{\dagger}$ & ${ }^{f} G_{12}$ & $15 \mathrm{GPa}$ \\
\hline Major Poisson's ratio ${ }^{\dagger}$ & $f_{v_{12}}$ & 0.21 \\
\hline Transverse shear modulus ${ }^{\dagger}$ & ${ }^{f} G_{23}$ & $7 \mathrm{GPa}$ \\
\hline Tensile strength & ${ }^{f} \sigma_{t}$ & $4410 \mathrm{MPa}$ \\
\hline Elongation at failure & $E L$ & $1.9 \%$ \\
\hline
\end{tabular}

Matrix properties

\begin{tabular}{lll}
\hline Type & \multicolumn{2}{l}{ HSC Epikote 4652 epoxy } \\
Density & ${ }^{m} \rho$ & $1200 \mathrm{~kg} / \mathrm{m}^{3}$ \\
Modulus & ${ }^{m} E$ & $4520 \mathrm{MPa}$ \\
Poisson's ratio & ${ }^{m} v$ & 0.358 \\
Tensile strength & ${ }^{m} \sigma_{t}$ & $68 \mathrm{MPa}$ \\
Fracture energy & ${ }^{m} g$ & $780 \mathrm{~J} / \mathrm{m}^{2}$ \\
\hline
\end{tabular}

UD lamina properties

Fibre volume fraction $\quad{ }^{f} v \quad 0.552$

Cured ply thickness $\quad h \quad 0.130 \mathrm{~mm}$

Weight $\quad w \quad 200 \mathrm{~g} / \mathrm{m}^{2}$

Longitudinal modulus ${ }^{\ddagger} \quad{ }^{c} E_{1} \quad 131.66 \mathrm{GPa}$

Transverse modulus

In-plane shear modulus *

Transverse shear modulus

Major Poisson's ratio

Through thickness Poisson's ratio

Nom $y$ nal values provided by manufactu

which were adopted from [42] and $\ddagger$ from

from nodel pre

,

ing. 1 presents the results of the t

presents the results of the through-
damage for a $50 \mathrm{~J}$ simulated impact

virtual coupon. The depicted example corresponds to a quarter section of the geometry during the loading.step at the instant Register for free ath te imum deflection. The damage variable plotted corresponds to the homogenised laminar damage $d_{e}$ on each Gauss point of the finite element $e$, which is defined as [44]:

$$
d_{e}=\frac{1}{V_{e}} \sum_{i=1}^{n}{ }^{L_{i}} v_{e}{ }^{L_{i}} d_{e}\left({ }^{f} d,^{m} d\right)
$$

being $V_{e}$ the volume of the element, $n$ the number of lamina collapsed in the element rounded up the nearest whole number, ${ }^{L_{i}} v_{e}$ the volumetric participation of the $i^{t h}$-lamina and ${ }^{L_{i}} d_{e}$ the damage of the $i^{t h}$-lamina, which is a function of the fibre ${ }^{f} d$ and matrix ${ }^{m} d$ damage parameters.

\subsection{Vibration response modeling}

To determine the natural frequencies and modal vectors of the damaged laminated plate, the specifically devised FE simulation code was used to solve the eigenvalue (modal) analysis. A numerical modal analysis was performed under free boundary conditions in order to avoid uncertainties when compared with experimental tests. The properties of the composite virtual coupon are the same as that for the previous numerical study except for the geometric model, which corresponds to the whole plate dimension. The mesh discretization was kept identical with 12 elements in the through-thickness direction (see Fig. 1). This was a requirement to merge the internal damage data set. Three-dimensional multilayer hexahedral elements with eight nodes and full integration were used, collapsing several layers into a single element. The predicted map of induced damage in terms of internal variables ${ }^{f} d$ and ${ }^{m} d$ was subsequently inserted in each homologous Gauss point, aiming to locally degrade the element constitutive behaviour.

In addition to the micro-mechanical approach described above, two additional modeling strategies were used to investigate the effect of impact damage upon the vibration response.

The second approach is based on a homogenised damage model at the mesoscale level, which has been used by different researchers to model the mechanical performance of composite lamina taking into account the different failure mechanisms $[10,22,45]$. Damage is characterised through the damage array $d=\left\{d_{i}\right\}$ for $i=1 \ldots 6$ where $d_{i} \in[0,1)$, whose components provide the influence of each damage mechanism on the effective compliance (see Eq. 20) coefficients as:

$$
S_{i j}^{d}=\frac{1}{\left(1-d_{i}\right)} S_{i j} \quad \text { for } \quad i=j
$$

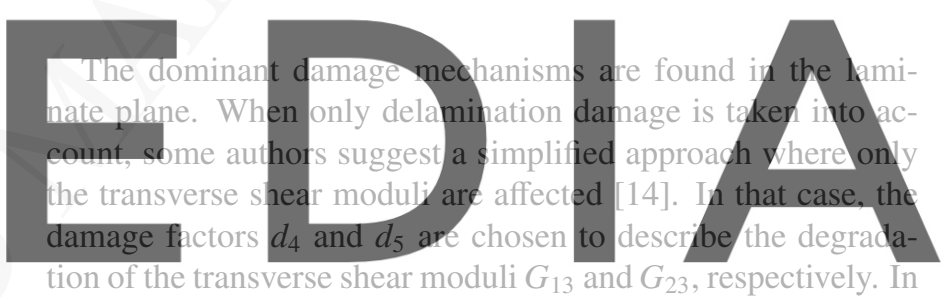
tion of the transverse shear moduli $G_{13}$ and $G_{23}$, respectively. In the present work the lower and upper bounds of both mesoscale

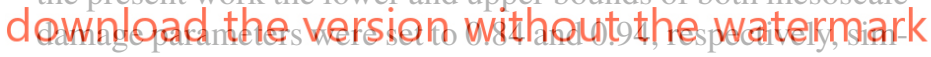
ilarly to previously reported works whose values were identified by fitting numerical and experimental results [10]. In order to compare the suitability and accuracy of this mesoscale approach, the same predicted map of induced damage was used to locally degrade the element constitutive behaviour, whereby the damaged extension was equivalent in both cases.

The third approach consists in physically subdividing the damaged virtual coupon by duplicating and detaching the nodes at the interface of adjacent elements at the location of the predicted delaminations. This can be similarly addressed by inserting a slim virtually degraded layer element between the upper and lower sublaminates within the delaminated regions. This strategy has been widely used previously [10, 18, 46]. In this work, slim interface solid elements were automatically created over the entire mesh. Then, the pristine constitutive models corresponding to the locations along the laminate thickness were assigned. Finally, at the location of predicted damaged elements the constitutive model of the interface elements was severely degraded (up to $1 \%$ ) to account for the discontinuity conditions. The influence of the interface element thickness was investigated comparing results of $2.50 \%$ and $25.0 \%$ of the nominal element thickness. As in the above cases, the damaged extent was equivalent thus simplifying comparisons. 


\section{Experimental procedure}

To validate the numerical predictions, an extensive experimental campaign was carried out to quantify the influence of low-velocity impact damage on the vibration response of CFRP laminated plates. The experimental programme involved two stages: drop-weight impact testing and modal testing performed before and after damaging the composite laminates. The experimental programme was conducted for a total of 48 monolithic composite plate specimens, whose properties are the same as those listed in Table 1 for the numerical study. Laminate curing was performed following a standard autoclave procedure. After the curing process, pristine coupons were examined using nondestructive ultrasonic inspection to assess the degree of compaction as well as detecting the presence of defects, porosities or delaminations.

\subsection{Drop-weight impact test}

An ASTM D7136 standard test method [43] was followed to determine the damage resistance of the laminated composite specimens subjected to a drop-weight impact event. A detailed description of the test conducted can be found in reference [15]. A total of 44 coupons were impacted with incident energy levels ranging from 6.6 to $70 \mathrm{~J}$, with a minimum of 2 and maximum of

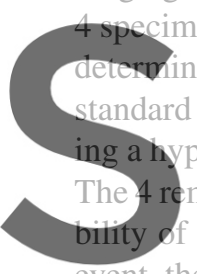
mens tested for each impact ned by the minimum height andard test method. The upper limit The 4 remaining specimens were rese modal testing on pristine
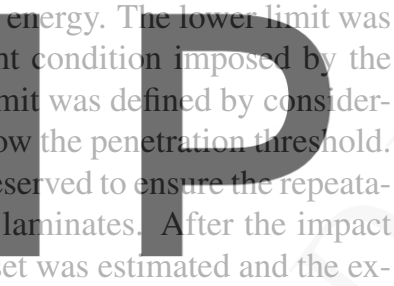

event, the interlaminar damage onset was estimated and the extent of induced delaminations was measured by using ultrasonic

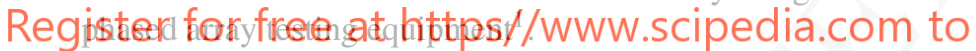

\subsection{Modal testing}

In order to obtain the modal parameters (frequencies and mode shapes) to examine the effect of the induced damage upon the vibration response, a modal testing of each pristine and damaged laminate plate was performed. Tests were carried out under free boundary conditions by suspending the coupons vertically. The real-time sampled signals (excitation and response) were measured and recorded in form of time series and processed into inertance frequency response function (FRF) data. Vibration measurements were performed using a singlereference roving hammer test. A mono-axial accelerometer ${ }^{2}$ was attached to a single degree of freedom (DoF) reference point on the top surface of the laminate, whereas the miniature transducer hammer ${ }^{3}$ roved around, exciting the specimen at 25 measuring DoFs, 5 evenly distributed in the direction of the width and 5 evenly distributed in the direction of the length. Because the delamination mode can introduce non-linearities

\footnotetext{
${ }^{1}$ OmniScan MX with standard phased array probe $5 \mathrm{MHz}$ linear array 64 elements.

${ }^{2}$ Accelerometer Bruel \& Kjaer 4518-003.

${ }^{3}$ Hammer Bruel \& Kjaer 8204.
}

[47], an effort was made to minimise them by using mini hammer transducer to create a low-level input excitation. In addition to the transverse modes of vibration, in-plane modes were also estimated by exciting the specimen at 5 evenly distributed locations on each lateral side. Both the applied excitation and the measured response ${ }^{4}$ were perpendicular to the coupon. Signals were averaged 3 times for each measurement point and the test frequency band was set to $20 \mathrm{kHz}$ with a resolution of $3.125 \mathrm{~Hz}$. Modal parameters were extracted by a fully automatic routine implemented in a Matlab code.

\section{Results and discussion}

The capability of the micro-mechanical numerical approach to modeling the effect of low-velocity impact-induced damage on the vibration response of CFRP laminates was assessed comparing the numerical results with the experimental ones obtained in the test campaign.

Attention was first focused on the prediction of the extent of damage in terms of projected delaminated area. Fig. 2 shows the comparison between the numerically predicted and experimentally measured internal induced damage by means of $\mathrm{C}$-scan ultrasonic images, as a function of incident kinetic energy. Experimental data plotted represent the mean values with

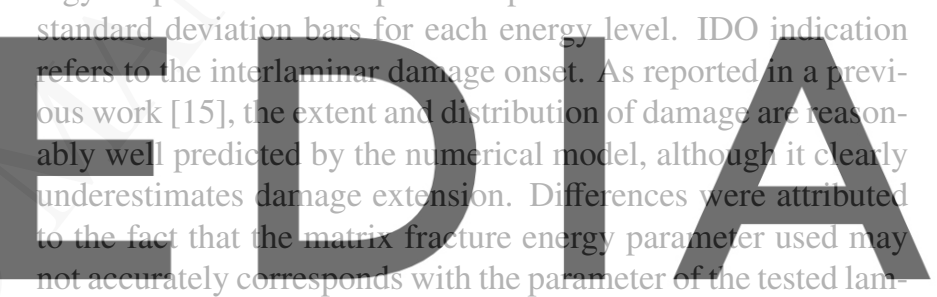

inates. The change in slope corresponds with the onset of fibre

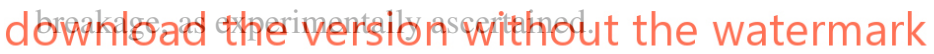

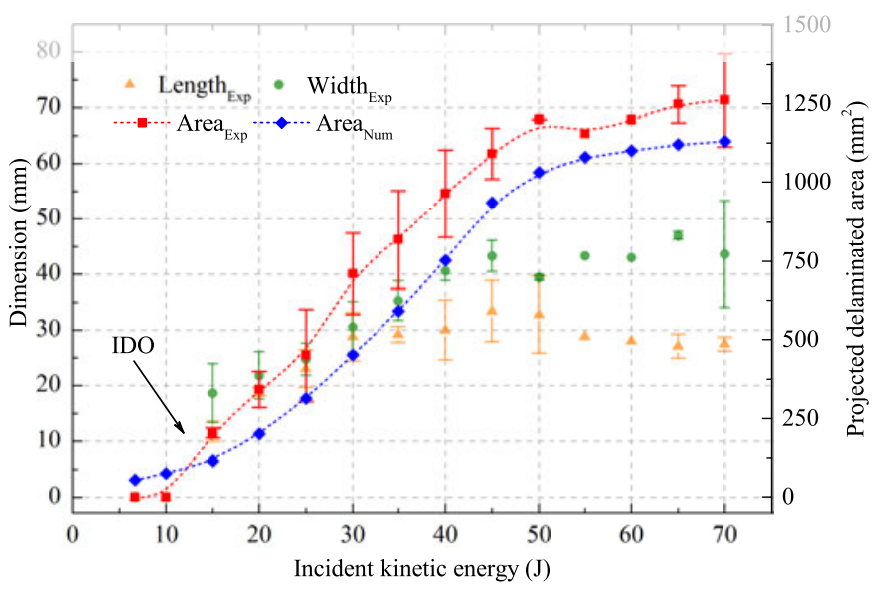

Figure 2: Ultrasonic testing results of the estimated area, length, width and numerical prediction of the projected delaminated area as a function of incident kinetic energy. IDO refers to the interlaminar damage onset.

A series of preliminary modal tests were performed for validation purposes. Table 2 collects the experimentally determined

\footnotetext{
${ }^{4}$ Data acquisition system Bruel \& Kjaer 3050-B-6/0.
} 
Table 2: Experimental and numerical correlation between natural frequencies and eigenfrequencies of an aluminium and a CFRP laminate reference specimen.

\begin{tabular}{|c|c|c|c|c|c|c|}
\hline & \multicolumn{3}{|c|}{ Aluminium specimen } & \multicolumn{3}{|c|}{ CFRP pristine specimen } \\
\hline Mode & $\operatorname{Exp}(\mathrm{Hz})$ & $\mathrm{H} 8(\mathrm{~Hz})$ & Diff $(\%)$ & $\operatorname{Exp}(\mathrm{Hz})$ & $\mathrm{H} 8(\mathrm{~Hz})$ & Diff $(\%)$ \\
\hline (1 11$)$ & 1259.9 & 1264.6 & 0.37 & 1250.4 & 1245.4 & -0.41 \\
\hline (2 0$)$ & 1400.9 & 1402.0 & 0.08 & 1404.2 & 1381.8 & -1.60 \\
\hline (2 1) & 2888.2 & 2915.5 & 0.95 & 2804.1 & 2828.3 & 0.86 \\
\hline$\left(\begin{array}{l}0 \\
0\end{array}\right)$ & 3222.0 & 3220.9 & -0.03 & 3001.5 & 2954.9 & -1.55 \\
\hline (3 0 ) & 3704.8 & 3671.5 & -0.90 & 3568.1 & 3498.9 & -1.94 \\
\hline (1 2) & 4284.8 & 4321.3 & 0.85 & 4131.6 & 4076.8 & -1.33 \\
\hline (3 1 ) & 5401.7 & 5390.6 & -0.21 & 5170.8 & 5119.8 & -0.99 \\
\hline (2 2) & 6137.2 & 6118.3 & -0.31 & 5806.6 & 5730.2 & -1.32 \\
\hline (4 0) & 7753.5 & 7715.2 & -0.49 & 7297.6 & 7228.8 & -0.94 \\
\hline$\left(\begin{array}{ll}0 & 3\end{array}\right)$ & 8536.9 & 8432.3 & -1.23 & 7711.1 & 7578.2 & -1.72 \\
\hline (3 2) & 9093.8 & 9062.2 & -0.35 & 8339.0 & 8253.7 & -1.02 \\
\hline$\left(\begin{array}{ll}4 & 1\end{array}\right)$ & 9232.4 & 9180.3 & -0.56 & 8530.5 & 8512.5 & -0.21 \\
\hline (1 3) & 9424.9 & 9321.8 & -1.09 & 8444.9 & 8311.2 & -1.58 \\
\hline In-plane bending & 12491.9 & 12536.3 & 0.36 & 13944.6 & 14314.7 & 2.65 \\
\hline In-plane shear & 16132.4 & 16202.5 & 0.43 & 18123.0 & 18522.2 & 2.20 \\
\hline In-plane compression & 16627.6 & 16528.1 & -0.60 & 18537.7 & 18965.6 & 2.31 \\
\hline
\end{tabular}

natural frequencies and the estimated eigenfrequencies of an aluminium reference specimen ${ }^{5}$ and a CFRP pristine laminate specimen. The minimum number of modes estimated on each test specimen limits the number of transverse modes analysed to 13 , whereas the test frequency band limits the number of inplane modes to 3 because these modes are in the range of 13-19 $\mathrm{kHz}$. The labels $(a b)$ identify each mode shape, in which $a$ and

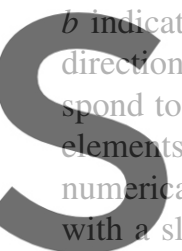
e the number of nodal lines and lengthwise direction, respectively.
direction. In
nent with ex

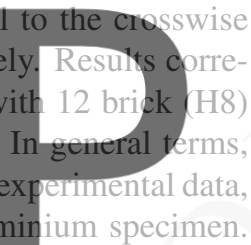

The aluminium plate results suggest that the ideally supposed free boundary conditions and the mesh discretization are suit-

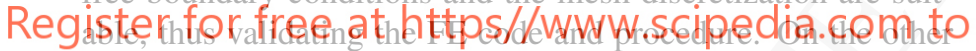
hand, the assumed mechanical properties of the constituent materials (Table 1 ) together with the expressions employed to calculate the effective engineering constants (Eq. 9-13), allowed us to successfully estimate the eigenfrequencies of the pristine laminate. Major differences are observed on the in-plane modes, which are independent of the through-thickness mesh refinement. It is noteworthy that transverse modes estimation shows mostly a softening behaviour in contrast to the in-plane modes estimation that shows stiffening. These differences arise due to the inherent experimental error, the inaccuracies of the elastic properties and the thickness non-uniformity (below 2\%), among others.

The capability of the three different scale-modeling strategies used to investigate the effect of impact damage upon the vibration response are compared to experimental results in Figs. 3 and 4. The experimental data plotted represent mean values of the percentage frequency changes with standard deviation bars for each impact energy level. The shaded area indicates presence of fibre breakage. Numerical results correspond to the predictions of the different modelling strategies such as the ad-

\footnotetext{
${ }^{5}$ Aluminium sample size: $150.15 \times 100.95 \times 5.99 \mathrm{~mm}^{3}$. Elastic properties: $E=70 \mathrm{GPa}, v=0.33$ and $\rho=2654.35 \mathrm{~kg} / \mathrm{m}^{3}$.
}

dressed micro-mechanical approach by decoupling also the effect of fibre damage, the mesoscale approach based on a degradation of the transverse shear moduli $G_{13}$ and $G_{23}$, as well as the approach consisting in inserting a slim virtually degraded layer elements between the upper and lower sublaminates within the interface of the delaminated regions, as previously explained.

In general terms, numerical simulations reproduce a variation of eigenfrequencies as impact energy increases. Nonetheless,
markedly different trends between experimental results and nu-
mericalpredictions are observed. While the micro-mechanical
approach yields a reasonably accurate estimation over all in-
pact energy ranges, mesoscale and interface approaches predic-
tions significantly depend on the danage or interface parameter settings, respectively. For instance, settings dependency

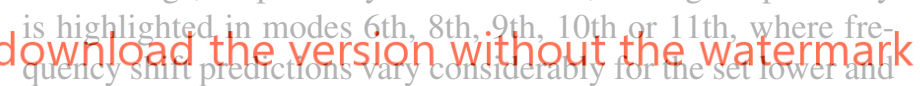
upper bounds.

It is worth noting that both the mesoscale and the interface approaches are aimed to represent solely the effect of interply decohesion. Accordingly, a direct dependency exists with the delaminated area. This relation can be observed in shift predictions (e.g. see mode 11 th) showing a decreasing trend consistent with the increasing amount of damaged area depicted in Fig. 2. Regardless, other modes visibly distance themselves from this dependence thus underlining the role of fibre breakage. As a first approximation and in order to investigate the significance of fibre damage on the vibration response, eigenfrequencies shifts were calculated by cancelling the effect of damage on fibres, i.e. ${ }^{f} d=0$. Those results correspond to the represented undamaged fibres curves, showing noticeable differences after the fibre damage onset. It should be noted that this hypothetical condition corresponds to an unrealistic situation, since if fibres are not considered to degrade, other failure mechanisms must dissipate the system energy during the impact event, thus leading to an increase of the matrix damaged area that it is not being considered here. Furthermore, as observed in Fig. 4, fibre degradation has a significant effect upon the in-plane modes. Results reveal that the micro-mechanical approach allowed us to reasonably reproduce this experimen- 

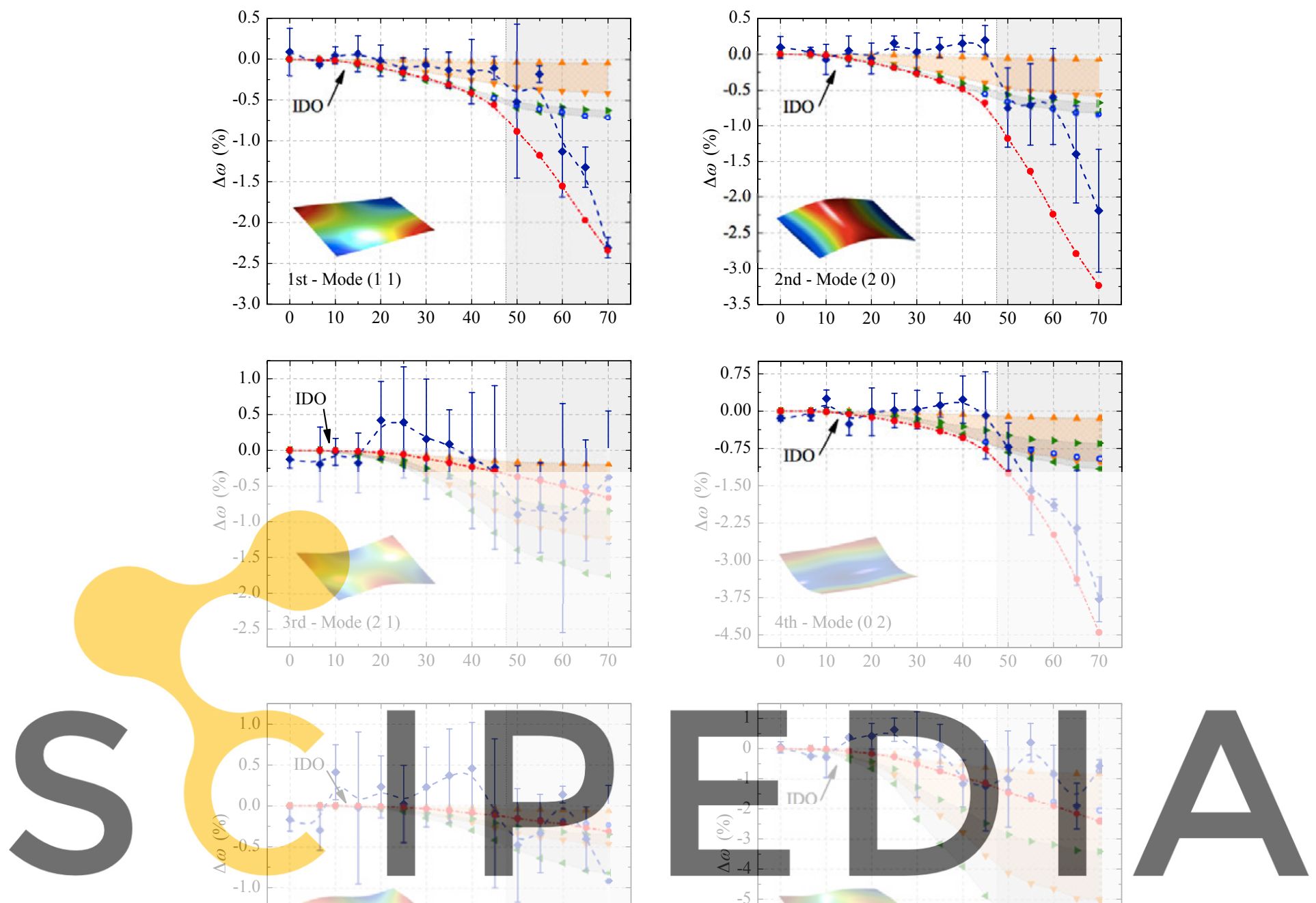

Register for free at https//www.scipedia.com to downtload the version without the watermark
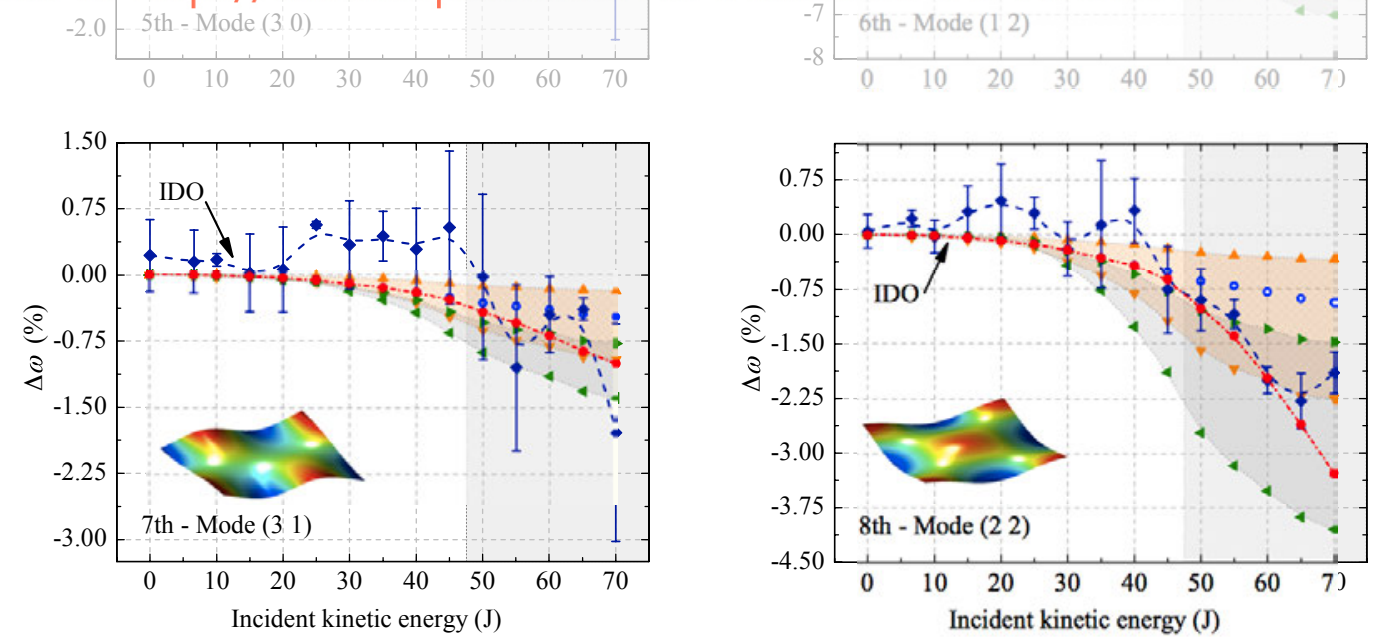

$-\bullet-$ Experimental - - - Micro-mechanical approach

Undamaged fibres $\approx$ Meso-scale approach $\left(G_{13^{*}} G_{23^{3}}\right) \leqslant$ Irterface

Figure 3: Experimental and numerical predictions of the percentage frequency changes for different modeling approaches as a function of incident kinetic energy of the first 8 transverse modes (follow in Fig. 4). IDO refers to the interlaminar damage onset.

tally observed behaviour.

\section{Conclusions}

A FE modelling approach based on a micro-mechanical de9 scription of low-velocity impact-induced damage on CFRP 

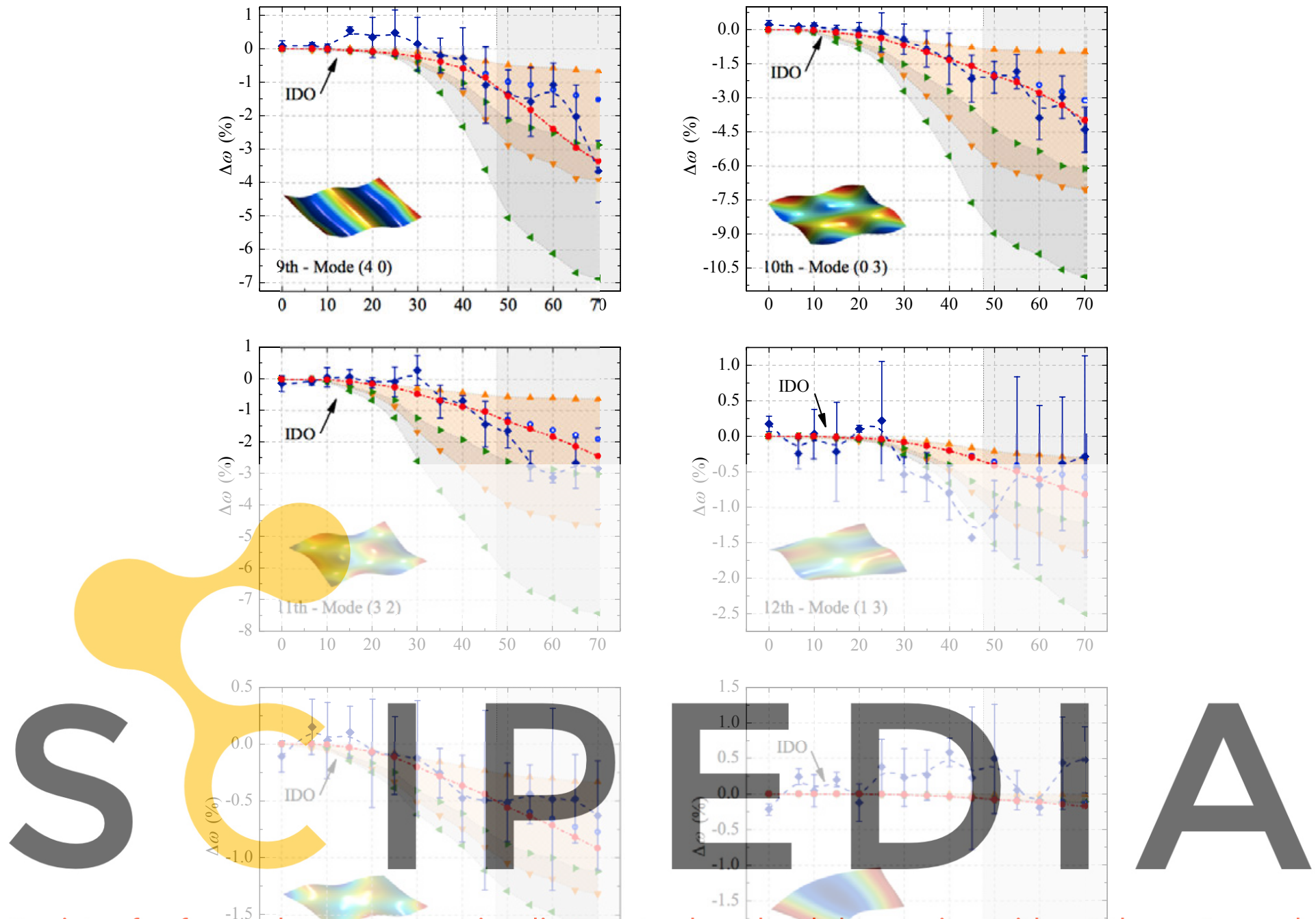

Register for free at https//hwww.scipedia.com to
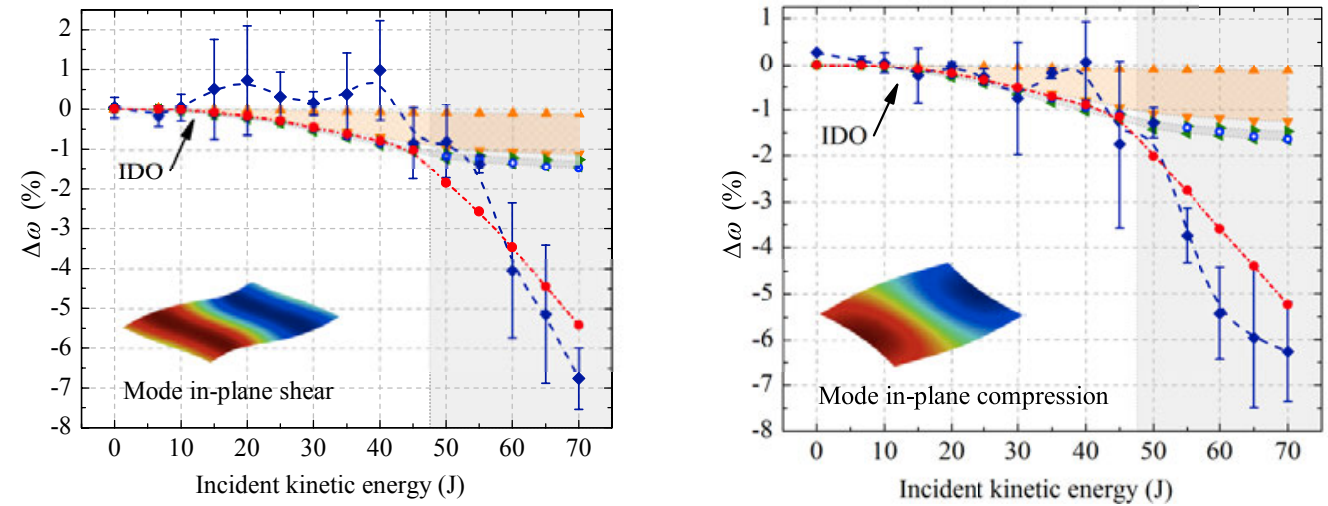

- - - Experimental - - - Micro-mechanical approach

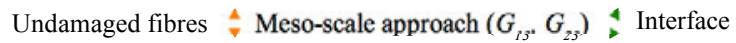

Figure 4: Experimental and numerical predictions of the percentage frequency changes for different modeling approaches as a function of incident kinetic energy of the following 5 transverse modes (comes from Fig. 3) and first 3 in-plane modes. IDO refers to the interlaminar damage onset.

laminated plates was investigated to analyse its effect upon the vibration response. The map of internal induced damage was firstly determined through the previously developed serial- parallel (SP) continuum approach [37, 31], wherein two compatibility equations define the stress equilibrium and establish the strain compatibility between the composite and the con- 
stituent materials. Subsequently, eigenvalue analysis was addressed to determine the modal response of impacted laminates. The validity of the modeling approach to successfully reproduce the vibration response of impacted coupons was assessed through a comparison with experimental measurements, showing a good correlation over all impact energy range evaluated.

Among the findings drawn from this study, it is shown that fibre breakage exerts a significant influence upon the in-plane vibration modes. On the other hand, the micro-mechanical approach overcomes several drawbacks of the other examined methods. Thus, for example, the abrupt and drastic global reduction of dominant stiffness components by using a homogenised scalar value on the mesoscale approach has been shown to be physically unrealistic, since this assumption is comparable to assuming an ideally brittle post-failure behaviour. Through the present micro-mechanical approach the progressive degradation of the constituent materials can be accounted for, thus providing a more realistic representation of the internal damage. Furthermore, by means of the interfacebased approach, the insertion of slim virtually degraded layer elements within the delaminated regions entails an increase in the number of elements and, consequently, the computational cost is increased. On the micro-mechanical approach, intraply and interply damages are captured within the same framework thus does not require the explicit inclusion of individual plies. Hence, several layers can be collapsed into a single element, which results in a computationally less demanding formulation.

In summary, the present micro-mechanical modeling approach is shown to be a promising numerical tool to be used in model-based vibration methods for impact damage identification routines. Studies to investigate the capability and suitability for modelling higher impact regimes on large structures will be the subject of future research.

\section{Acknowledgements}

This work has been supported by the European Research Council under the Advanced Grant: ERC-2012-AdG 320815 COMP-DES-MAT "Advanced tools for computational design of engineering materials" and UPC Mobility Research Grant PDI 2010. All this support is gratefully acknowledged. Special thanks also to Dr. Fernando Rastellini and Dr. Xavier Martínez for the collaboration, support and useful discussions. Three anonymous reviewers are thanked for constructive suggestions.

\section{Appendix: The explicit solution of FE simulation}

The general dynamic differential equation that describes the impact problem addressed may be written as:

$$
\mathbf{M} \ddot{\mathbf{x}}(t)+\mathbf{p}(\mathbf{x}(t), \dot{\mathbf{x}}(t))=\mathbf{f}(\mathbf{x}(t))
$$

being $\mathbf{M}$ the mass matrix of the system, $\mathbf{x}(t), \dot{\mathbf{x}}(t)$ and $\ddot{\mathbf{x}}(t)$ the displacement, velocities and accelerations vectors, respectively, $\mathbf{p}(\mathbf{x}(t), \dot{\mathbf{x}}(t))$ represents the internal forces and $\mathbf{f}(\mathbf{x}(t))$ the external ones.
The FE code ComPack uses an explicit time integration scheme given its adequacy to the impact problem dealt. The solution at the time $t_{n+1}=t_{n}+\Delta t_{n+1}$ is explicitly determined from the known configuration at the step $n$ by using a finite difference-based time integration scheme, in which $\Delta t$ is the time step employed and $n$ the number of steps used in the integration procedure.

To ensure stability and accuracy of the solution, the size of the time step is limited according to the CFL condition [40] by:

$$
\Delta t \leq \Delta t_{c r}=\frac{2}{\omega_{\max }}
$$

where the $\Delta t_{c r}$ indicates critical time and $\omega_{\max }=2 \pi f_{\max }$ is the maximum frequency of the discrete problem. The nodal translations are obtained sequentially integrating the three uncoupled expressions:

$$
\begin{gathered}
\ddot{\boldsymbol{x}}_{n}=\frac{1}{M}\left[\boldsymbol{f}(\boldsymbol{x}(t))_{n}-\boldsymbol{p}(\boldsymbol{x}(t), \dot{\boldsymbol{x}}(t))_{n}-\xi_{n}\right] \\
\dot{\boldsymbol{x}}_{n+\frac{1}{2}}=\dot{\boldsymbol{x}}_{n-\frac{1}{2}}+\frac{1}{2} \ddot{\boldsymbol{x}}_{n}\left(\Delta t_{n-1}+\Delta t_{n}\right) \\
\boldsymbol{x}_{n+1}=\boldsymbol{x}_{n}+\dot{\boldsymbol{x}}_{n+\frac{1}{2}} \Delta t_{n}
\end{gathered}
$$

where $\boldsymbol{x}, \dot{\boldsymbol{x}}$ and $\ddot{\boldsymbol{x}}$ denote the nodal displacements, nodal velocities and nodal accelerations vectors, respectively, $M$ represents the local mass associated to each node and $\xi$ denotes a nodal damping component applied to accelerations.

\section{References}

[1] S. R. Reid, G. Zho, Impact behaviour of fibre-reinforced composite materials and structures, CRC Press, 2000.

[2] J. M. Hodgkinson, Mechanical testing of advanced fibre composites, CRC Press, 2000.

[3] S. W. Doebling, C. R. Farrar, M. B. Prime, D. W. Shevitz, Damage Identification and Health Monitoring of Structural and Mechanical Systems from Changes in their Vibration Characteristics: A Literature Review., Los Alamos National Laboratory report, (LA-13070-MS) (1996).

[4] Y. Zou, L. Tong, G. P. Steven, Vibration-Based Model-Dependent Damage (Delamination) Identification and Health Monitoring for Composite Structures: a Review, J Sound Vib 230 (2000) 357-378.

[5] C. N. Della, D. Shu, Vibration of Delaminated Composite Laminates: A Review, Appl Mech Rev 60 (2007) 1-20.

[6] M. A. Pérez, L. Gil, S. Oller, Impact damage identification in composite laminates using vibration testing, Compos Struct 108 (2014) $267-276$.

[7] M. A. Pérez, L. Gil, M. Sánchez, S. Oller, Comparative experimental analysis of the effect caused by artificial and real induced damage in composite laminates, Compos Struct 112 (2014) 169-178.

[8] S. S. Kessler, S. M. Spearing, M. J. Atalla, C. E. Cesnik, C. Soutis, Damage detection in composite materials using frequency response methods, Compos B Eng 33 (2002) 87-95.

[9] L. H. Yam, Nondestructive Detection of Internal Delamination by Vibration-based Method for Composite Plates, J Compos Mater 38 (2004) 2183-2198.

[10] J. Frieden, J. Cugnoni, J. Botsis, T. Gmür, Vibration-based characterization of impact induced delamination in composite plates using embedded FBG sensors and numerical modelling, Compos B Eng 42 (2011) 607613.

[11] W. Fan, P. Qiao, A 2-D continuous wavelet transform of mode shape data for damage detection of plate structures, Int J Solids Struct 46 (2009) 4379-4395.

[12] H. Niemann, J. Morlier, A. Shahdin, Y. Gourinat, Damage localization using experimental modal parameters and topology optimization, Mech Syst Signal Process 24 (2010) 636-652. 
[13] J. V. Araújo dos Santos, C. M. Mota Soares, C. A. Mota Soares, N. M. M. Maia, Structural damage identification in laminated structures using FRF data, Compos Struct 67 (2005) 239-249.

[14] J. Frieden, J. Cugnoni, J. Botsis, T. Gmür, Low energy impact damage monitoring of composites using dynamic strain signals from FBG sensors - Part II: Damage identification, Compos Struct 94 (2012) 593-600.

[15] M. A. Pérez, X. Martínez, S. Oller, L. Gil, F. Rastellini, F. Flores, Impact damage prediction in carbon fiber-reinforced laminated composite using the matrix-reinforced mixing theory, Compos Struct 104 (2013) 239 248.

[16] R. Joffe, A. Krasnikovs, J. Varna, COD-based simulation of transverse cracking and stiffness reduction in [S/90n]s laminates, Compos Sci Technol 61 (2001) $637-656$.

[17] E. J. Barbero, D. H. Cortes, A mechanistic model for transverse damage initiation, evolution, and stiffness reduction in laminated composites, Compos B Eng 41 (2010) 124 - 132

[18] L. H. Yam, Z. Wei, L. Cheng, W. O. Wong, Numerical analysis of multilayer composite plates with internal delamination, Comput Struct 82 (2004) 627-637.

[19] M. V. Donadon, L. Iannucci, B. G. Falzon, J. M. Hodgkinson, S. F. M. de Almeida, A progressive failure model for composite laminates subjected to low velocity impact damage, Comput Struct 86 (2008) 12321252.

[20] K. V. Williams, R. Vaziri, A. Poursartip, A physically based continuum damage mechanics model for thin laminated composite structures, Int $\mathrm{J}$ Solids Struct 40 (2003) 2267-2300.

[21] P. Maimí, P. Camanho, J. Mayugo, C. Dàvila, A continuum damage model for composite laminates: Part I: Constitutive model, Mech Mater 39 (2007) 897-908.

[22] C. Lopes, P. Camanho, Z. Gürdal, P. Maimí, E. Gonzàlez, Low-velocity impact damage on dispersed stacking sequence laminates. Part II: Numerical simulations, Compos Sci Technol 69 (2009) 937-947.

[23] C. Bouvet, B. Castanié, M. Bizeul, J.-J. Barrau, Low velocity impact modelling in laminate composite panels with discrete interface elements, Int J Solids Struct 46 (2009) 2809-2821.

[24] G. Z. Voyiadjis, Z. N. Taqieddin, P. I. Kattan, Micromechanical approach to damage mechanics of composite materials with fabric tensors, Compos B Eng 38 (2007) 862-877.

[25] G. Soni, S. Gupta, R. Singh, M. Mitra, W. Yan, Study of localized damage in composite laminates using micro-macro approach, Compos Struct (2014).

[26] M.-J. Pindera, H. Khatam, A. S. Drago, Y. Bansal, Micromechanics of spatially uniform heterogeneous media: A critical review and emerging approaches, Compos B Eng 40 (2009) 349-378.

[27] A. Tabiei, S. B. Aminjikarai, A strain-rate dependent micro-mechanical model with progressive post-failure behavior for predicting impact response of unidirectional composite laminates, Compos Struct 88 (2009) 65-82.

[28] P. Ladevèze, G. Lubineau, On a damage mesomodel for laminates:micro-meso relationships, possibilities and limits, Compos Sci Technol 61 (2000) 2149-2158.

[29] P. Ladevèze, G. Lubineau, D. Violeau, A Computational Damage Micromodel of Laminated Composites, Int J Fract 137 (2006) 139-150.

[30] D. Ivancevic, I. Smojver, Micromechanical damage modelling using a two-scale method for laminated composite structures, Compos Struct 108 (2014) 223-233.

[31] X. Martínez, F. Rastellini, S. Oller, F. Flores, E. Oñate, Computationally optimized formulation for the simulation of composite materials and delamination failures, Compos B Eng 42 (2011) 134-144.

[32] A. Eijo, E. Oñate, S. Oller, A numerical model of delamination in composite laminated beams using the LRZ beam element based on the refined zigzag theory, Compos Struct 104 (2013) 270 - 280.

[33] X. Martínez, S. Oller, E. Barbero, Study of delamination in composites by using the serial/parallel mixing theory and a damage formulation, in: Mechanical Response of Composites, volume 10 of Comput Methods Appl Sci, Springer Netherlands, 2008, pp. 119-140.

[34] J. Oliver, M. Cervera, S. Oller, Isotropic damage models and smeared crack analysis of concrete., Proceedings of SCI-C 1990 (1990) 945-958.

[35] L. Kachanov, Rupture time under creep conditions, Izv Akad Nauk SSSR Otd Tekhn Nauk 8 (1958) 26-31. In Russian.

[36] L. Kachanov, Rupture time under creep conditions, Int J Fract 97 (1999)
11-18.

[37] F. Rastellini, S. Oller, O. Salomón, E. Oñate, Composite materials nonlinear modelling for long fibre-reinforced laminates: Continuum basis, computational aspects and validations, Comput Struct 86 (2008) 879_ 896.

[38] X. Martínez, S. Oller, F. Rastellini, A. H. Barbat, A numerical procedure simulating RC structures reinforced with FRP using the serial/parallel mixing theory, Comput Struct 86 (2008) 1604-1618.

[39] L. P. Kollár, G. S. Springer, Mechanics of Composite Structures, Cambridge University Press, 2003.

[40] CIMNE and Quantech ATZ, Innovative Finite Element Code for nonlinear analysis of composite structures, CIMNE and Quantech ATZ, 2008-to present.

[41] E. Oñate, Structural Analysis with the Finite Element Method. Linear Statics: Volume 1, Springer, 2009

[42] P. Soden, Lamina properties, lay-up configurations and loading conditions for a range of fibre-reinforced composite laminates, Compos Sci Technol 58 (1998) 1011-1022.

[43] ASTM-D7136, Standard test method for measuring the damage resistance of a fibre-reinforced polymer matrix composite to a drop-weight impact event, Tech. rep. West Conshohocken (PA, USA): American Society for Testing and Materials (ASTM), 2007.

[44] S. Oller Aramayo, L. Nallim, S. Oller, An integrated procedure for the structural design of a composite rotor-hydrofoil of a water current turbine (WCT), Appl Compos Mater 20 (2013) 1273-1288.

[45] J. LLorca, C. González, J. M. Molina-Aldareguía, J. Segurado, R. Seltzer, F. Sket, M. Rodríguez, S. Sádaba, R. Muñoz, L. P. Canal, Multiscale Modeling of Composite Materials: a Roadmap Towards Virtual Testing, Adv Mater 23 (2011) 5130-5147.

[46] K. Alnefaie, Finite element modeling of composite plates with internal delamination, Compos Struct 90 (2009) 21-27.

[47] F. Aymerich, W. J. Staszewski, Impact damage detection in composite laminates using nonlinear acoustics, Compos A Appl Sci Manuf 41 (2010) 1084-1092. 